\title{
PERFIS MOTIVACIONAIS E GESTÃO DE PESSOAS NO VOLUNTARIADO
}

Lic. LEONARDO BONVENTI NUNES DE PAIVA

Centro Universitário Adventista de São Paulo, Brasil 


\title{
Resumen
}

Perfis motivacionais e gestão de pessoas no voluntariado. O voluntariado tem ganhado considerável atenção dentro da sociedade. É uma forma de demonstrar preocupação com o próximo, mas também pode estar carregado de objetivos pessoais e egoístas. Este estudo observa as relações entre o Terceiro Setor e o voluntariado, e busca identificar as reais motivações que levam os indivíduos a se envolverem em atividades voluntárias. Para isso, utilizou-se o modelo Volunteer Funcions Inventory que colheu respostas de 130 voluntários, e concluiu que dentre os seis perfis propostos, aquele relacionado aos valores, altruísmo e humanitarismo é o grande motivador dos indivíduos no voluntariado. Por fim, propõe-se uma reflexão sobre o processo de gestão de pessoas, associado a atração, recrutamento e retenção de voluntários, considerando de forma significativa os perfis motivacionais identificados, a fim de aprimorar os práticas e experiências voluntárias.

Palabras clave: voluntariado, motivação, atração, recrutamento, gestão de pessoas.

\begin{abstract}
Motivational Profiles and People Management in Volunteering. Volunteering has gained considerable attention within society. It is a way to show concern for others, but it can also be loaded with personal and selfish goals. This study looks at the relationship between the Third Sector and volunteering, and seeks to identify the real motivations that lead individuals to engage in voluntary activities. Therefore, the Volunteer Functions Inventory model was used, which collected responses from 130 volunteers, and concluded that among the six profiles proposed, the one related to values, altruism and humanitarianism is the great motivator of individuals in volunteering. Finally, we propose a reflection on the people management process, associated with attracting, recruiting and retaining volunteers, significantly considering the motivational profiles identified, in order to improve voluntary practices and experiences.
\end{abstract}

Keywords: volunteering, motivation, attraction, recruitment, people management.

Recibido: 19/08/2019

Aceptado: 02/03/2021 


\section{PERFIS MOTIVACIONAIS E GESTÃO DE PESSOAS NO VOLUNTARIADO}

Lic. LeONARDO BONVENTI NUNES DE PAIVA

Centro Universitário Adventista de São Paulo, Brasil

\section{Introdução}

Ao longo dos últimos anos a sociedade tem percebido uma crescente movimentação relacionada ao voluntariado. Essa experiência vem ganhando raízes cada vez mais profundas entre indivíduos que querem servir sua comunidade, seu país, e até mesmo pessoas carentes em outros continentes. A discussão em torno do voluntariado desperta o interesse de pesquisadores que buscam compreender quais são os fundamentos dessa motivação e quais os seus desdobramentos.

É correto afirmar que dentro do sistema social, o voluntariado se enquadra na perspectiva do Terceiro Setor, que possui características não governamentais e não lucrativas, é organizado, independente e tem o desafio de instigar a prestação de serviços de forma voluntária, através da doação de

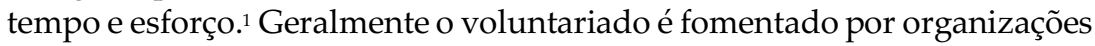
formais, com estruturas já estabelecidas e que mantém atividades constantes, ${ }^{2}$ bem como de maneira informal, que Jardel Augusto Gomes Rodrigues Alves, Layse Maria Leite Pereira e Carlos Eduardo Cavalcante definem como independente, que pode "levar a um impacto social ainda mais forte do que o já alcançado por organizações voluntárias formalizadas e arranjadas de modo burocrático e muitas vezes engessado".$^{3}$

1 Ruben Cesar Fernandes, Privado, porém público: o terceiro setor na América Latina (Rio de Janeiro: Relume-Dumará, 1994), 19-20.

2 Rosangela Cenci et al., "O voluntariado social e suas interrelações com a sustentabilidade", Revista Administração em Diálogo 18, no. 2 (2016): 21.

3 Jardel Augusto Gomes Rodrigues Alves, Layse Maria Leite Pereira e Carlos Eduardo Cavalcante, "Luzes em uníssono: gestão de pessoas no voluntariado informal", Revista Eletrônica Gestão \& Sociedade 12, no. 33 (2018): 2457. 
Para tanto, faz-se expressivo o uso do termo voluntário para qualificar grupos ou indivíduos, organizados ou não, associados à uma entidade, instituição, ou simplesmente aqueles que exercem atividade voluntária de forma individual, isolada ou informal.

De acordo com relatório da United States Volunteers (UNV) de 2017, um total de 6.501 indivíduos, com mais de 100 profissões diferentes, serviram em 38 organizações parceiras do voluntariado das Nações Unidas, em um total de 131 países. Dentre todos, 1.820 voluntários têm idade inferior a 29 anos. $^{4}$

Alguns voluntários estão dispostos a dedicar meses e até anos de suas vidas em projetos próximos ou distantes de sua realidade e do seu país. Há também, os projetos chamados de curto prazo, geralmente mais comuns e menos custosos, com duração de poucos dias, e marcados por atividades intensas incluídas em uma rotina bem planejada, dentro ou fora do país de origem. De modo geral, estes projetos objetivam suprir algumas necessidades específicas das comunidades atendidas, condicionadas à dignidade humana, saúde física, estilo de vida, higiene, habitação, educação, etc., e são avaliados em sua possibilidade de execução e modelados às limitações do orçamento, abastecido com recursos de organizações, padrinhos, e dos próprios voluntários.

O objeto desse estudo são esses voluntários, que se dedicam em atividades sociais e comunitárias dentro e fora do país, fornecendo seu tempo, talento e recursos em projetos fomentados por instituições filantrópicas, abertos e disponíveis a quem desejar colaborar. Desse modo, induz-se então à seguinte questão: o que motiva esses indivíduos a serem atraídos e recrutados ao envolvimento em projetos voluntários?

Este estudo tem como principal objetivo identificar os perfis motivacionais e as razões que levam os indivíduos a se engajarem em serviços de voluntariado, formais ou informais, dentro ou fora do país. Seguido por objetivos específicos, como refletir acerca da relação entre as motivações ao voluntariado e conceitos da gestão de pessoas atrelados a processos de atração, recrutamento e retenção de voluntários, bem como propor elementos que contribuam de forma significativa para maior eficiência desses processos no voluntariado, visando aprimorar as relações entre líderes e liderados.

O autor considera de bastante estima este estudo por estar associado a projetos voluntários, e por experienciar a perspectiva de gestão e liderança em projetos dentro e fora do Brasil, crendo que é possível analisar e inspirar

4 "Transforming UNV for the Globlal Goals", UN Volunteers, acessado em 2 de setembro de 2018, https://www.unv.org/annual-report/annual-report-2017.

https://doi.org/10.17162/recm.v18i1-2.1159 
motivações, a fim de desenvolver projetos que sejam bem-sucedidos em seus objetivos do início ao fim.

No sentido de alcançar os objetivos propostos, foi necessário obter dados manuseáveis acerca das motivações dos voluntários, para tanto, optouse por fazer uso do sistema Volunteer Functions Inventory (VFI), elaborado por E. Gil Clary, Mark Snyder e Robert Ridge, ${ }^{5}$ que demonstraram confiabilidade, aplicabilidade e reconhecimento. Foram colhidas informações de 130 voluntários que dedicaram seu tempo em projetos dentro e fora do país, por definição como uma amostra por conveniência não-probabilística.

O sistema VFI elucida seis motivações prováveis que induzem ao voluntariado, avaliados por meio de 30 questões assertivas utilizando a escala Likert (de 1 a 7) no qual são orientados de menor (1) para maior relevância (7), destacando por fim o resultado dentro das áreas: valores, compreensão, social, carreira, protecionismo e aperfeiçoamento. O modelo foi testado e validado no Brasil pelos pesquisadores Ronaldo Pilati e Maria Alexandra Gaiofatto Hees, ${ }^{6}$ utilizado em outros estudos, e adaptado para diferentes realidades, por autores como Ana Filipa Monteiro Marques da Silva; ${ }^{7}$ Raysa Oliveira de Medeiros; ${ }^{8}$ Siomara Roberta de Siqueira, Elma Lourdes Campos Pavone Zoboli e Silvia Helena Bastos de Paula; e, Alves, Pereira e Cavalcante. ${ }^{10}$

A seguir, o trabalho apresentará referenciais teóricos acerca do voluntariado e sua ligação com o terceiro setor, as motivações e a gestão de pessoas, bem como metodologia, análise e interpretação dos dados, e suas devidas considerações finais.

5 E. Gil Clary, Mark Snyder e Robert Ridge, “Volunteers' Motivations", Nonprofit Management and Leadership 2, no. 4 (1992): 333-350.

6 Ronaldo Pilati e Maria Alexandra Gaiofatto Hees, "Evidências de validade de uma versão brasileira do Inventário de Funções do Voluntariado - IFV", Psico-USF 16, no. 3 (2011): 275-284.

7 Ana Filipa Monteiro Marques da Silva, “Motivações e efeitos do voluntariado jovem: fatores de retenção organizacional" (Dissertação de mestrado, Instituto Universitário de Lisboa, 2012): 27-37.

8 Raysa Oliveira de Medeiros, "Perfil e motivação de voluntários para o engajamento no trabalho sem fins lucrativos" (Dissertação de mestrado, Universidade Federal do Rio Grande do Norte, 2014): 32-85.

9 Siomara Roberta de Siqueira, Elma Lourdes Campos Pavone Zoboli e Silvia Helena Bastos de Paula, "Voluntariado em saúde na graduação e a formação de valores humanísticos, sigilo, privacidade e confidencialidade de pacientes", Revista de Graduação USP 2, no. 3, (2017): 25-33.

10 Alves, Pereira e Cavalcante, “Luzes em uníssono”, 2455-2479. 


\section{Referencial teórico}

Há material considerável acerca do voluntariado e suas motivações, como também acerca da gestão de pessoas, todos abarcados pelo Terceiro Setor, e é por meio destes três aspectos que pretende-se construir uma perspectiva sobre o assunto para enfim, conclui-lo. Estes aspectos serão tratados à luz de autores e fundamentos no propósito de alcançar o objetivo descrito na introdução.

\subsection{Terceiro Setor e o voluntariado}

Ao longo dos séculos da estruturação social, elaboraram-se formas e modelos de suprir as necessidades da sociedade civil, o que ficou conhecido como sistema social. Para Rosangela Cenci, Rosaria Maria Ferreira Silva, Simone Sehnem e Eliane Salete Filippim, o terceiro setor é uma rede de organizações privadas autônomas, que não distribui lucros, e pretende atender as necessidades e propósitos públicos, refletindo mudanças sociais e tecnológicas. ${ }^{11}$

Ele está relacionado à participação de cidadãos, de forma espontânea, em ações que buscam alcançar um benefício público de interesse social comum, sem estarem ligados à contratos formais de trabalho, tampouco esperam recompensas financeiras imediatas. ${ }^{12}$ Por sua vez, Ismenia Guedes Duarte, Carlos Eduardo Cavalcante e Ricardo Ribeiro Rocha Marques ${ }^{13}$ preferem associar a alta demanda do terceiro setor à incapacidade do Estado em atender e suprir às necessidades da sociedade nas diversas áreas que a compõem, como saúde, educação, lazer, meio ambiente, e tantas outras mais, formando, através dos movimentos sociais uma forma de organização específica: a de fins públicos, não ligada ao estado.

A existência dessas organizações está intimamente relacionada à doação de tempo e recursos de cidadãos voluntários, que formam o seu corpo técnico, possuindo grande compromisso com o desenvolvimento social, como organizações de ação, atuando de forma flexível, inovadora, rápida e no território onde se encontram..$^{14}$

11 Cenci et al., “O voluntariado social”, 9.

12 Alves, Pereira e Cavalcante, “Luzes em uníssono”, 2460-2461.

13 Ismenia Guedes Duarte, Carlos Eduardo Cavalcante e Ricardo Ribeiro Rocha Marques, "Gestão de pessoas no terceiro setor: motivações dos voluntários da fundação Cidade Viva", Revista Organizações em Contexto 13, no. 25 (2017): 100.

14 Cenci et al., "O voluntariado social”, 11. 
Norman Johnson prefere distinguir os termos voluntariado e organizações voluntárias, e argumenta que o voluntariado é definido por "pessoas que não recebem remuneração pelo que fazem, ainda que possam ser reembolsadas pelos gastos que efetuam no exercício de suas ações". ${ }^{15}$ Cátia Sofia Martins complementa a definição do termo como "um comportamento não obrigatório, sujeito a uma planificação, mantido ao longo do tempo, sem expectativa de recompensa monetária, que beneficia outros não íntimos e que ocorre dentro de um contexto organizacional". ${ }^{16}$ Já a expressão organizações voluntárias remete aos sistemas ou organizações não governamentais vinculadas ao terceiro setor, que também são conhecidos como setor voluntário, o qual abarca "desde organizações de autoajuda ou ajuda mútua, cooperativas dos mais diferentes tipos, associações profissionais, agregados vicinais e até grupos de pressão". ${ }^{17}$

O setor voluntário geralmente está relacionado aos interesses pessoais de seus participantes, e à defesa de causas sociais e políticas. São organizações formais eventualmente concebidas e mantidas por cidadãos que desejam contribuir positivamente com sua sociedade através da prestação de serviços, e assim torná-la um ambiente melhor para todos.

Para Ana Amelia Mascarenhas Camargos, o trabalho voluntário ganhou forma por meio das atuações religiosas de caridade na sociedade ocidental. ${ }^{18}$ Com o passar dos anos, o voluntariado foi atraindo maior atenção, passando a abranger um campo mais extenso do que a própria atividade religiosa. Entretanto, o conceito de caridade continua a impulsionar qualquer envolvimento voluntário. ${ }^{19}$

De forma mais prática, a Organização das Nações Unidas define voluntário como "o jovem, adulto ou idoso que, devido a seu interesse pessoal e

15 Norman Johnson, El estado de bienestar en transición: la teoria y la pratica del pluralismo de bienestar (Madrid: Ministério de Trabajo y Seguridad Social, 1990), 135.

16 Cátia Sofia Martins, “Motivação para realizar voluntariado: estudos segundo as abordagens funcionalista e da autodeterminação" (Dissertação de Doutorado, Universidade do Algarve - Faculdade de Ciências Humanas e Sociais, Gambelas, Portugal, 2013), 17.

17 Potyara A. P. Pereira, "A nova divisão social do bem-estar e o retorno do voluntariado", Serviço Social \& Sociedade 34, no. 73 (2003): 89.

18 Ana Amelia Mascarenhas Camargos, Direito do trabalho no Terceiro Setor (São Paulo: Saraiva, 2008), 64-66

19 Ana Rosa da Silva, Alexandre Cappellozza e Felipe Zambaldi, “Antecedentes do engajamento e da intenção em permanecer em projetos sociais: um estudo em instituições de ensino superior do estado de São Paulo", Teoria e Prática em Administração 7, no. 1 (2017): 83-84. 
seu espírito cívico, dedica parte do seu tempo, sem remuneração, a diversas formas de atividades de bem estar social ou outros campos". ${ }^{20}$ Nesse sentido, o voluntariado remete ao envolvimento de indivíduos em determinados seguimentos ou áreas de atuação em função do bem-estar social, promovendo a valorização de pessoas e o sentimento de reciprocidade, doação de si e confiança. Trata-se de algo imaterial, que transpõe barreiras étnicas ou culturais, e propõe a oportunidade da paz com a participação de todos.

No Brasil, a Lei Federal no 9.608 de 1998, que dispõe sobre o exercício do voluntariado e regulamenta sua participação na sociedade, no artigo 1으, considera o serviço voluntário como: "a atividade não remunerada, prestada por pessoa física a entidade pública de qualquer natureza, ou a instituição privada de fins não lucrativos, que tenha objetivos cívicos, culturais, educacionais, científicos, recreativos ou de assistência social, inclusive mutualidade". Continuando em seu Parágrafo Único, completa que "o serviço voluntário não gera vínculo empregatício, assim como também não gera qualquer obrigação trabalhista, previdenciária ou afim" ${ }^{21}$

O objetivo do voluntário é poder usar o que ele tem e o que ele é em benefício de outros, despertando seus valores humanos de altruísmo e solidariedade como uma forma de compaixão, para ofertar aos que não tiveram determinadas oportunidades ou escolhas, as mesmas que um dia the foram servidas. $\mathrm{O}$ "voluntariado pode contribuir para o desenvolvimento de uma forma da sociedade que reforça o sentido de solidariedade e favorece o acolhimento e a integração dos indivíduos na comunidade na qual estão inseridos". ${ }^{22}$

O Independence Sector, uma organização norte-americana que reúne um conjunto de entidades sem fins lucrativos, como fundações e corporações que promovem o bem comum, estima que o valor por hora de um voluntário em ação seja de 28,54 dólares, e pressupõe que haja cerca de 63 milhões de voluntários apenas nos Estados Unidos, realizado diversas contribuições à sociedade civil, desde atos simples, até os mais complexos. ${ }^{23}$

"O trabalho voluntário e a ONU", UNIC Rio de Janeiro: Centro de Informação das Nações Unidas no Brasil, acessado em 07 de setembro de 2017, https://unicrio.org.br/voluntariado/.

21 “Lei Federal no 9608, de 18 de fevereiro de 1998”, Presidência da República - Casa Civil: Subchefia para Assuntos Jurídicos, acessado em 13 de março de 2019, http://www.planalto.gov.br/ccivil_03/Leis/L9608.htm.

22 Cenci et al., "O voluntariado social", 15.

23 "Value of Volunteer Time", Independent Sector, acessado em 03 de maio de 2019, https://independentsector.org/value-of-volunteer-time-2020/. 
Segundo levantamento realizado pela Fundação Itaú Social e Instituto Datafolha, $11 \%$ da população brasileira se dedica ao voluntariado continuamente. Outros $28 \%$ praticaram ações voluntárias e ainda $72 \%$ nunca se envolveram. ${ }^{24}$

A identidade do voluntário é construída através da maneira como esse indivíduo se identifica e interioriza o seu papel no desenvolvimento de uma atividade voluntária. Essa atividade, por sua vez, se for em alto nível e envolvente àquele indivíduo, produzirá uma forte identidade voluntária, o que contribuirá para a reincidência em serviços voluntários, ou o que é chamado de voluntarismo contínuo. ${ }^{25}$

Compreendendo corretamente as definições apresentadas, é necessário refletir sobre as pressuposições que induzem à determinado comportamento voluntário, as motivações dos indivíduos para seu envolvimento com práticas voluntárias, formais ou informais. Motivações essas que serão detalhadas na sequência.

\subsection{Motivação: instrumento inseparável do voluntariado}

A motivação humana tem sido objeto de estudo nas mais diferentes áreas, e intriga pesquisadores, que buscam ansiosamente poder compreendê-la em profundidade. $\mathrm{O}$ termo motivação, basicamente pode ser definido como um "conjunto de processos que dão ao comportamento uma intensidade, uma direção determinada e uma forma de desenvolvimento próprias da atividade individual" ${ }^{26}$

Na perspectiva de Gary P. Latham e Craig C. Pinder, a motivação se realiza como um processo psicológico complexo que resulta de uma interação entre o indivíduo e o ambiente que o rodeia. ${ }^{27}$ A psicologia interpreta a motivação como condições que despertam comportamentos geralmente re-

24 "Pesquisa sobre voluntários no Brasil: Resultados 2014", Pesquisa da Fundação Itaú Social, acessado em 21 de fevereiro de 2019, https://d13q7w9s0p5d73.cloudfront.net/uploads/itau/document/file/614/a082e3a3993a-4bd4-a29e-9e1eb82ee0f7.pdf.

25 Pedro Piccoli e Christiane Kleinübing Godoi, “Motivação para o trabalho voluntário contínuo: uma pesquisa etnográfica oliem uma organização espírita" Organizações $\mathcal{E}$ Sociedade 19, no. 62 (2012): 403.

26 O Dicionário Houaiss da Língua Portuguesa, s.v. "Motivação".

27 Gary P. Latham e Craig C. Pinder, "Work Motivation Theory and Research at the dawn of the Twenty-First Century" Annual Review of Psychology 56 (2005): 486.

https://doi.org/10.17162/recm.v18i1-2.1159 
lacionados a recompensas, que variam de eventos fisiológicos até interações sociais. Acredita-se inclusive que as pessoas raramente têm consciência dessas influências motivadoras. ${ }^{28}$

Pode-se ainda, verificar outras tantas análises sobre a motivação e suas ramificações, como intrínseca ou extrínseca, que Bruna Bruno e Damiano Fiorillo compreendem como influências importantes no voluntariado, ${ }^{29}$ mas a fim de obter maior plausibilidade na observação dos resultados de forma gerencial e estratégica, optou-se por considerar neste estudo apenas a motivação, de maneira geral e uniforme, como simplificação analítica.

James M. Kouzes e Barry Z. Posner acreditam que a motivação deva estar presente quando as pessoas estão fazendo o melhor que podem..$^{30}$ Do ponto de vista gerencial, Cecilia Whitaker Bergamini acredita que todas as pessoas têm motivação suficiente para alcançar suas aspirações, o que ela chama de potencial sinergético, e estão desejosas de entrar em ação, avançar em direção aos objetivos pelos quais vale a pena trabalhar, e sentiremse realizadas por serem úteis e satisfazerem suas necessidades pessoais de crescimento e desenvolvimento, que pode ser avaliado por meio do reconhecimento, materialização, ascensão empresarial, etc. ${ }^{31}$

Como pode-se perceber, toda ação humana exige uma fagulha que seja de motivação, na busca por satisfazer objetivos particulares, ou de um grupo de pessoas com as mesmas idealizações, que pode ter aspectos associados a atividades profissionais, políticas, religiosas, sociais, bem como voluntárias.

Ana Rosa da Silva, Alexandre Cappellozza e Felipe Zambaldi acreditam que há pelo menos duas grandes razões para o envolvimento das pessoas no trabalho voluntário: 1) o altruísmo, o ato de fazer o bem à quem precisa, um auto sacrifício sem aparente recompensa pessoal; e, 2) o interesse em desenvolver aptidões profissionais através da experiência proporcionada pelo trabalho social, agregando também objetivos pessoais e sociais, além de quaisquer outros propósitos, e em contrapartida, o voluntário usa dessa experiência para continuar servindo ${ }^{32}$. Eduardo Cavalcante, Washington

28 Linda L. Davidoff. Introdução à psicologia, 3 ed. (São Paulo: Makron Books, 2001), 325330.

29 Bruna Bruno e Damiano Fiorillo, "Why Without Pay? Intrinsic Motivation in the Unpaid Labour Supply", Journal of Socio-Economics 41, no. 5 (2012): 659-699.

30 James M. Kouzes e Barry Z. Posner, O desafio da liderança: como conseguir feitos extraordinários em organizações (Rio de Janeiro: Campus, 1991), 33-34.

31 Cecilia Whitaker Bergamini, Liderança: Administração do sentido (São Paulo: Atlas, 1994), 78.

32 da Silva, Cappellozza e Zambaldi, “Antecedentes do engajamento", 83-84. 
José de Souza e Anderson Luiz Rezende Mól preferem nomear essas razões, respectivamente, como elementos unidimensionais, e multidimensionais. ${ }^{33}$

A compreensão que existem outros fatores motivacionais, além do altruísmo, influenciando o voluntariado é ampla entre os pesquisadores da área. Mesmo ocupando o primeiro lugar na incidência da motivação, os fatores altruístas e ideológicos logo são seguidos pelos chamados motivos egoístas, entendidos como motivações de crescimento pessoal, de status, sociais e materiais ${ }^{34}$. Vania D'Angelo Dohme entende que esses demais fatores são inconscientes buscas por recompensas pessoais: oportunidades de utilizar suas habilidades, se desenvolver pessoalmente, ser reconhecido na sociedade em que vive e pertencer a um grupo. ${ }^{35}$ Alves, Pereira e Cavalcante consideram esses fatores como de interesses individualistas e objetivos particulares. ${ }^{36}$

A quantidade de fatores pode mudar, e suas nomenclaturas também. Helmut K. Anheier e Lester M. Salamon elencam em três os fatores motivacionais que conduzem o voluntariado: 1) motivos altruístas (sentimento de solidariedade, empatia e dignidade), 2) motivos instrumentais (aquisição de experiência e habilidades, satisfação pessoal como voluntário), e 3) motivos de obrigação (dever moral, religioso e até mesmo político de contribuir na sociedade). ${ }^{37}$

Cavalcante, Souza e Mól desenvolveram um modelo visando uma hierarquia dos fatores motivacionais relacionada ao contexto brasileiro, composta por cinco fatores: altruísta (desejo de promover o bem-estar mediante doação pessoal), afetivo (agregado ao coletivo, desejo de fazer o bem aos outros por meio de um grupo), amigável (desejo de um indivíduo de ser aceito por um grupo), ajustado (interesse no autodesenvolvimento e busca de competências e habilidades específicas), e ajuizado (desejo de obtenção ou preservação de vantagens próprias, individuais ou coletivas). ${ }^{38}$

33 Carlos Eduardo Cavalcante, Washington José de Souza e Anderson Luiz Rezende Mól, "Motivação de voluntários: proposição de um modelo teórico", Revista de Administração Mackenzie 16, no. 1 (2015): 131.

34 André Ofenhejm Mascarenhas, Felipe Zambaldi e Carmen Augusta Varela, "Motivação em programas de voluntariado empresarial: um estudo de caso", Organizações em Contexto 9, no. 7 (2013): 234-236.

35 Vania D'Angelo Dohme, Voluntariado, equipes produtivas: Como liderar ou fazer parte de uma delas (São Paulo: Mackenzie, 2001), 1-210.

36 Alves, Pereira e Cavalcante, “Luzes em uníssono”, 2463.

37 Helmut K. Anheier e Lester M. Salamon, "Volunteering in Cross-National Perspective: Initial Comparisons", Law and Contemporary Problems 62, no.4 (1999): 11.

38 Cavalcante, de Souza e Mól, “Motivação de voluntários”, 132-135. 
Nesse contexto, Clary, Snyder e Ridge foram precursores na identificação de possíveis fatores motivacionais ao voluntariado, que em sua perspectiva se dividem em seis perfis:

1) Valores: o voluntariado acontece na expressão de valores, como humanitarismo e altruísmo, que são defendidos por indivíduos que demonstram preocupação com a sociedade.

2) Compreensão: a possibilidade de exercitar o conhecimento e habilidades, além da busca por experiências de aprendizado.

3) Social: o indivíduo crê que dentro do voluntariado será possível conhecer outras pessoas e desenvolver novos relacionamentos, além de estreitar laços sociais nos quais já esteja incluído.

4) Carreira: visualização de experiências em uma carreira pretendida para a vida, bem como os benefícios relacionados à estas carreiras.

5) Protecionismo: tentativa de proteger seu próprio ego, a fim de reduzir sentimentos negativos próprios, como culpa, ou minimizar e até mesmo fugir dos problemas pessoais.

6) Aperfeiçoamento: pretensão de desenvolvimento pessoal, associados ao crescimento individual e de autoestima, envolvendo sentimentos positivos acerca de si mesmo. ${ }^{39}$

A motivação é o centro de toda a capacidade humana no despertar de novos instintos e vontades, e permite alcançá-los e satisfazê-los. Não há como realizar qualquer atividade, remunerada ou não, se não houver a incitação suficiente através da motivação. O grande desafio é fundir todas as ideias sobre motivação em uma construção sólida acerca do melhor desenvolvimento e gestão de pessoas dentro do voluntariado, e utilizar desses conceitos para atrair, recrutar e manter indivíduos motivados e engajados em projetos voluntários.

\subsection{Gestão de pessoas ligada ao voluntariado}

O conceito de gestão de pessoas surge a partir da necessidade de uma empresa se organizar para gerenciar e orientar o comportamento humano no trabalho. Em suma, as organizações têm a incumbência e o privilégio de gerenciar o comportamento de seus colaboradores, de modo a alcançar seus objetivos, cumprindo os propósitos da empresa.40 
A gestão de pessoas é parte da atividade entendida como Recursos Humanos, que recebe funções como gerenciamento, recrutamento, contratação e outras tarefas ligadas ao capital humano. Ganhou notoriedade a partir do surgimento da Teoria das Relações Humanas, no início do século XX, que trouxe uma nova concepção acerca da natureza do homem, destacando que os trabalhadores são criaturas sociais complexas, com sentimentos, desejos, temores, e personalidades próprias, levando ao entendimento de que o seu comportamento e produtividade são resultados de muitos fatores motivacionais e relações sociais. ${ }^{41}$

Alcançar resultados positivos em qualquer empreendimento depende de uma série de fatores, incluindo uma gestão eficiente de pessoas, que busque desenvolver a motivação e o engajamento necessários nos indivíduos pertencentes aos processos. Dentro da perspectiva do voluntariado, as condições não são diferentes, remunerados ou não, os participantes precisam estar motivados e bem geridos, e essa tarefa deve ser extremamente cautelosa. A correta interação com pessoas que dedicam seu tempo, talentos e bens pessoais, é de extrema necessidade para manter o engajamento eficiente e satisfatório em projetos idealizados ou em execução.

Erlaine Binotto, Alessandra do Nascimento Lima, Elisabete Stradiotto Siqueira e Fabiula Meneguete Vides da Silva, percebem uma crescente adesão a gestão de pessoas dentro do setor voluntário. Ainda que não sejam muitas as organizações que mantenham uma gestão organizacional devidamente qualificada para tratar dos recursos humanos, ela vem recebendo atenção que objetiva uma atuação com competência nos projetos de voluntariado.42 Uma gestão eficaz de pessoas é importante para não comprometer os resultados e impactar a retenção de voluntários. Também é responsável por aperfeiçoar, inovar, e trazer instrumentos que permitam a prestação de contas e divulgação dos resultados, bem como gerenciar o voluntariado em todas as suas dinâmicas. ${ }^{43}$

Um estudo realizado por Jeffrey L. Brudney e Tamara G. Nezhina em que foi avaliada a eficácia de um programa formalizado de voluntariado, concluiu que alguns elementos são essenciais para alcançar os objetivos traçados em programas de voluntariado: políticas escritas para condução do

41 Idalberto Chiavenato, Introdução à Teoria Geral da Administração, $9^{\circ}$ ed. (Barueri: Manole, 2014), 118-119.

42 Binotto et al., "Gestão de pessoas", 227.

43 Sheila Patrícia Ramos Beckhauser e Maria José Carvalho de Souza Domingues, “A profissionalização da gestão do voluntariado: um estudo de caso do departamento de voluntários do Hospital Israelita Albert Einstein", Saúde e Sociedade 26, no. 4, (2017): 1041. 
programa, descrições de trabalho dos voluntários, treinamento básico de saída e atuação, e recursos para gerir os voluntários ${ }^{4}$. Ressalta-se também que a postura de gerenciamento de voluntários associada a abordagem de negócios, com formalização e controle excessivos sobre a experiência voluntária, tenha impacto negativo no envolvimento dos indivíduos, reduzindo o engajamento e as oportunidades previstas no desenvolvimento pessoal e profissional dos voluntários ${ }^{45}$.

Outra dificuldade aparente na gestão do voluntariado está nos processos de recrutamento e retenção de pessoas. Entende-se que o trabalho voluntário está sujeito a iniciativa particular de seus colaboradores, e são eles quem decidem permanecer atuantes nos projetos, pois como dito, não existe vínculo de obrigação. Dohme lembra que o trabalho voluntário, embora seja uma ação espontânea e gratuita, não dispensa regras, planejamento e organização, bem como os fundamentos da gestão de pessoas46.

Aplicando os conceitos de recrutamento - processo pelo qual a organização atrai candidatos potencialmente qualificados para ocupar os cargos disponíveis ${ }^{47}$ - ao contexto do voluntariado, é possível visualizar a carência de material humano nas ações voluntárias, sendo atraídos e retidos de forma positiva em novos projetos.

De acordo com Beckhauser e Domingues, esse recrutamento é construído por cinco etapas: 1) captação de voluntários através da divulgação constante de novos projetos; 2) seleção dos candidatos considerando suas habilidades, intenções, disponibilidades, sensibilidades, entusiasmo, atitudes, etc.; 3) contrato de adesão com o tipo de trabalho, frequência, tempo de dedicação, etc.; 4) integração do voluntário na estrutura da organização e seus parâmetros, como regras, regimentos, organogramas, objetivos, missão, visão e valores; e por fim, 5) orientação, que envolve treinamento, informação e conhecimento, promovendo ao novo voluntário tudo o que ele precisa saber para ser bem sucedido em sua empreitada ${ }^{48}$.

É importante ressaltar que o processo de recrutamento em um ambiente empresarial, com vagas reais e assalariadas é diferente do que acontece na

44 Jeffrey L. Brudney e Tamara G. Nezhina, "What Is Old Is New Again: Achieving Effectiveness with Volunteer Programs in Kazakhstan", Voluntas 16, no. 3 (2005): 293308.

45 Martha L. Barnes e Erin K. Sharpe, “Looking Beyond Traditional Volunteer Management: A Case Study of an Alternative Approach to Volunteer Engagement in Parks and Recreation", Voluntas 20, no. 2 (2009): 173.

46 Dohme, Voluntariado, 21.

47 Ana Cristina Limongi França, Práticas de recursos humanos - PRH: conceitos, ferramentas e procedimentos (São Paulo: Atlas, 2007), 29-30.

48 Beckhauser e Domingues, “A profissionalização da gestão do voluntariado", 1029. 
esfera do voluntariado, onde não há vínculo empregatício, e praticamente nenhuma recompensa financeira. É preciso considerar o que motiva os indivíduos ao envolvimento no voluntariado, e por meio desse entendimento, refletir sobre práticas de atração, recrutamento e retenção de novos voluntários, a fim de oferecer as recompensas que buscam encontrar. O próximo passo trata-se da proposta de pesquisa que busca compreender e traçar esses perfis motivacionais.

\section{Metodologia}

A pesquisa formulada para atender aos objetivos previstos na introdução e responder o questionamento proposto acerca da motivação de voluntários é definida como descritiva de caráter quantitativo, de campo, na forma a observar, coletar e analisar os dados recebidos por meio de um questionário, adaptado à plataforma digital Google Forms.

Ao todo, o questionário digital contém 39 questões, divididas em duas etapas: a primeira composta pela identificação demográfica (idade; sexo; escolaridade; se há prática de religião; se houve prática de voluntariado; se houve prática de voluntariado em outro país; e se sim, qual país; qual a duração da última experiência voluntária; e se haveria possibilidade de uma nova experiência voluntária por parte dos entrevistados); seguida pelo bloco de questões assertivas que visam identificar os perfis motivacionais dos indivíduos, denominado VFI, ou, como traduzido por Pedro Piccoli e Christiane Kleinübing Godoi, Inventário de Funções Voluntárias (IFV). ${ }^{49}$

Esse questionário é um modelo proposto por Clary, Snyder e Ridge ${ }^{50}$, testado por E. Gil Clary, M. Snyder, R. D. Ridge, J. Copeland, A. A. Stukas, J. Haugen e P. Miene, ${ }^{51}$ e validado no Brasil pelos pesquisadores Pilati e Hess. ${ }^{52}$ Neste estudo, optou-se por utilizar a versão traduzida de Ana F. da Silva. ${ }^{53} \mathrm{O}$ instrumento é composto por trinta questões assertivas que identificam fatores de motivação ao voluntariado alocados em seis perfis, descritos pelos autores como: valores, compreensão, social, carreira, protecio-

50 Clary, Snyder e Ridge, “Volunteers' Motivations”, 333-350.

51 E. Gil Clary et al., "Understanding and Assessing the Motivations of Volunteers: A Functional Approach", Journal of Personality and Social Psychology 74, no. 6 (1998): 1516-1530.

52 Pilati e Hess, “Evidências de validade”, 275-284.

53 de Silva, "Motivações e efeitos do voluntariado jovem", 64-68. 
nismo e aperfeiçoamento. A mensuração das questões foi baseada em escala Likert de sete pontos, sendo 1 nada verdadeiro, e 7 totalmente verdadeiro.

A população da pesquisa são participantes de projetos realizados dentro e fora do país, promovidos pelo Centro Universitário Adventista de São Paulo (UNASP), campus Engenheiro Coelho, por meio de seus departamentos: Pastoral Universitária, For the Love of the World (FLOW) e Adventist Frontier Mission (AFM), entre o período de julho de 2015 a julho de 2018, que compreende a confiabilidade de registros mais precisos de participantes, tomados com maior controle pela instituição desde então.

As listagens dos participantes dos projetos de voluntariado foram cedidas pelos departamentos, totalizando 449 voluntários, contendo nomes e endereços eletrônicos, por meio dos quais foi-lhes enviado o questionário para preenchimento. $\mathrm{O}$ tempo de pesquisa durou 15 dias, período entre 13 e 28 de novembro de 2018, e colheu uma amostra com 130 voluntários respondentes $(28,95 \%)$, que foi analisada e quantificada, como entende-se na sequência.

\section{Discussão e análise dos dados}

Com os dados em mãos, foi possível traçar as características demográficas dos respondentes, dos quais o público feminino representa $54,6 \%$, enquanto que o público masculino soma $45,4 \%$ do total. Esse fato apresenta relação com os trabalhos de Alves, Pereira e Cavalcante, ${ }^{54}$ e de Silva, Cappellozza e Zambaldi, ${ }^{55}$ onde a predominância feminina também foi percebida.

Acerca da escolaridade, 51,5\% dos pesquisados cursavam o Ensino Superior, enquanto $26,9 \%$ já o haviam concluído, e outros $20 \%$ frequentavam programas de pós-graduação. Situação facilmente explicada pelo fato da pesquisa ser aplicada à voluntários de projetos fomentados por um Centro Universitário.

Com relação a idade, a amostra variou de 17 a 68 anos, e a maior representatividade apareceu na faixa etária entre 20 e 25 anos, com $69,2 \%$ das respostas. Considerando como perfil jovem aqueles que possuem até 29 anos, a pesquisa verificou uma incidência de 107 respondentes que se enquadraram. Para efeitos de melhor análise do VFI, preferiu-se dividir a amostra em três faixas etárias: 17 a 23 anos, 24 a 29 anos, e 30 a 68 anos.

54 Alves, Pereira e Cavalcante, “Luzes em uníssono”, 2465.

55 da Silva, Cappellozza e Zambaldi, “Antecedentes do engajamento", 93.

https://doi.org/10.17162/recm.v18i1-2.1159 
Dos 130 pesquisados, 95,4\% afirmaram praticar alguma religião, enquanto apenas $4,6 \%$ não praticavam. Fato paralelo à confessionalidade cristã da instituição objeto de estudo.

Outro dado curioso é que $90,8 \%$ declararam ter participado de projetos voluntários fora do país, e 33,1\% tiveram experiências voluntárias em mais de um país. Houve um total de 196 menções a países, que somaram 40 diferentes países. Os cinco mais mencionados, e a sua incidência na pesquisa: Brasil, 43; Paraguai, 33; Peru, 25; Tailândia, 10; e Albânia, 9.

Já sobre o período total da última experiência de voluntariado, percebeu-se que $72,3 \%$ declararam terem sido voluntários por um período inferior a 30 dias. Outros $13,1 \%$ se enquadraram em um período entre 7 a 12 meses de voluntariado, e ainda outros 7,7\%, em um período superior a 12 meses. Os dados de períodos entre 1 e 6 meses não foram significativos.

Por fim, nesta primeira etapa, a última pergunta dizia respeito a possibilidade de retorno à algum novo projeto de voluntariado, e a resposta unânime dos participantes foi positiva, demonstrando uma excelente taxa de retenção dos voluntários.

Os resultados da análise do questionário serão apresentados iniciando com as médias calculadas das questões por perfil motivacional, agrupadas nos respectivos gráficos. Em seguida, as questões serão associadas com os dados demográficos, e então, será possível visualizar os perfis motivacionais em sua classificação geral.

\subsection{Volunteer Funcions Inventory}

O questionário VFI, elaborado inicialmente por Clary, Snyder e Rigde tinha como objetivo apresentar possíveis razões pelas quais as pessoas se envolvem em um projeto voluntário. Os autores criam que o indivíduo se envolve em práticas voluntárias não apenas essencialmente por ser altruísta, mas as razões para esse envolvimento poderiam ser variadas e associadas aos objetivos e propósitos pessoais, não necessariamente compartilhados entre os voluntários ${ }^{56}$.

Com esse pensamento, os autores elencaram seis possíveis perfis motivacionais dentro do voluntariado: valores, compreensão, aperfeiçoamento, carreira, social e protecionismo. Cada perfil é norteado por cinco questões, posicionadas em ordem aleatória no questionário, totalizando as trinta questões originalmente concebidas, e são mensuradas por uma escala Likert, com variação entre 1 e 7 , sendo 1 menos importante e 7 mais importante. Para fins de melhor manuseio e análise dos resultados, a variação foi

56 Clary, Snyder e Ridge, “Volunteers' Motivations", 333-350.

https://doi.org/10.17162/recm.v18i1-2.1159 
abreviada e suas alternativas agrupadas da seguinte maneira: irrelevante (1 a 3), neutro (4), e relevante (5 a 7).

O primeiro perfil motivacional, de Valores (Q3, Q8, Q16, Q19, Q22), é expressado pelo humanitarismo e altruísmo, defendidos por indivíduos que demonstram preocupação com a sociedade. As questões desse perfil detém as maiores médias de relevância dentre toda a pesquisa, conforme demonstra o Gráfico 1. Dentre elas, a menor média de relevância é da questão "8. Estou preocupado com o grupo que especificamente vou/estou a apoiar" com 73,85\%. Já a questão "19. Sinto que é importante ajudar os outros" se destaca como tendo a maior média de relevância de todo o questionário: 98,46\%.

Gráfico 1 - Perfil motivacional: Valores

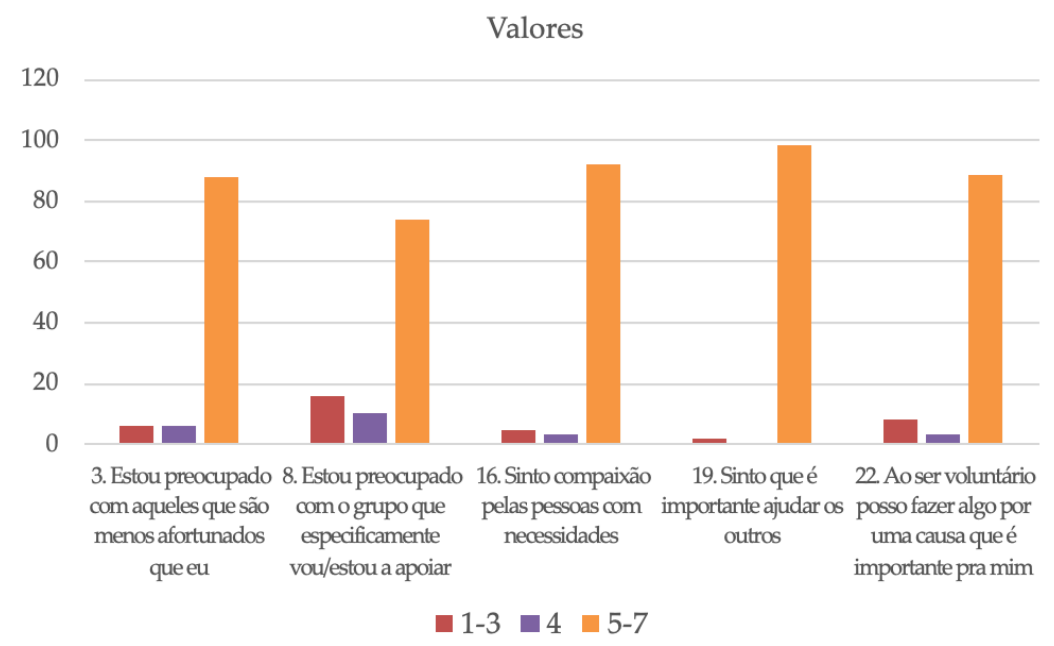

Já o perfil Compreensão (Q12, Q14, Q18, Q25, Q30), que diz respeito ao exercício do conhecimento e habilidades, além da busca por experiências de aprendizado no voluntariado, também apresenta médias elevadas de relevância, como sinaliza o Gráfico 2, nas questões "25. No voluntariado posso aprender a lidar com uma variedade de pessoas" com $95,38 \%$, e " 14 . O voluntariado me ajuda a ter uma nova perspectiva sobre as coisas" com 94,62\%. 
Gráfico 2 - Perfil motivacional: Compreensão

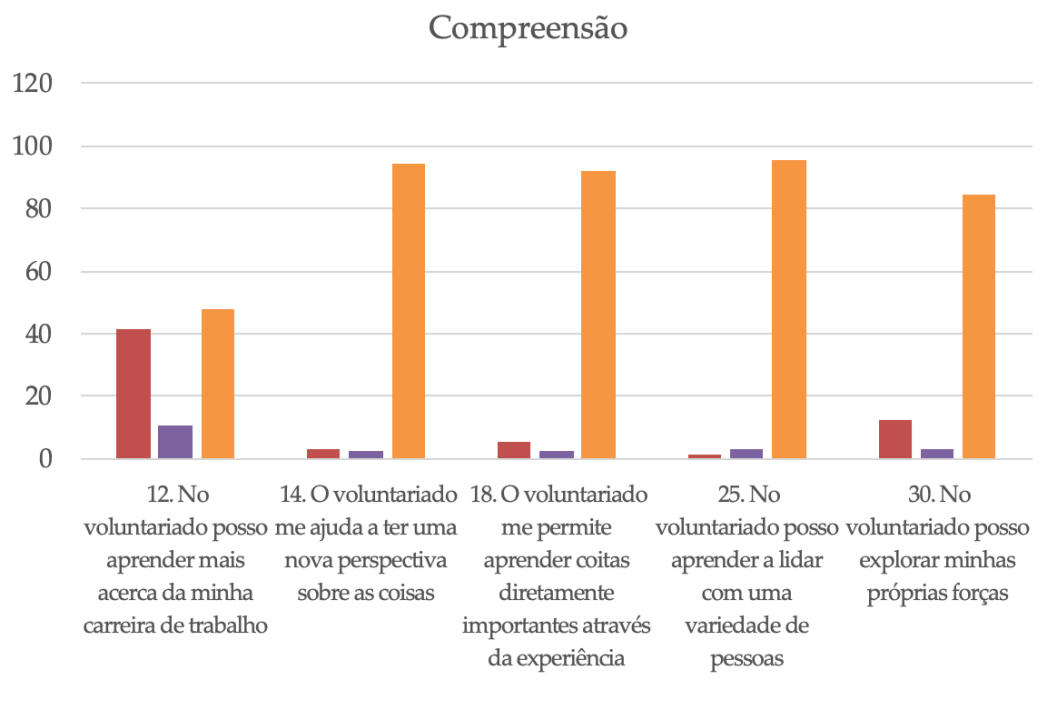

-1-3 4 口 5-7

O perfil Aperfeiçoamento (Q5, Q13, Q26, Q27, Q29), relacionado a pretensão de desenvolvimento pessoal, crescimento individual e autoestima, envolvendo sentimentos positivos acerca de si mesmo, alcançou 82,31\% de relevância na questão "29. O voluntariado é uma forma de fazer novos amigos", como aponta o Gráfico 3. Também já é possível perceber uma sinalização maior de questões consideradas irrelevantes, com médias desde $10 \%$ até $31,54 \%$.

Gráfico 3 - Perfil motivacional: Aperfeiçoamento

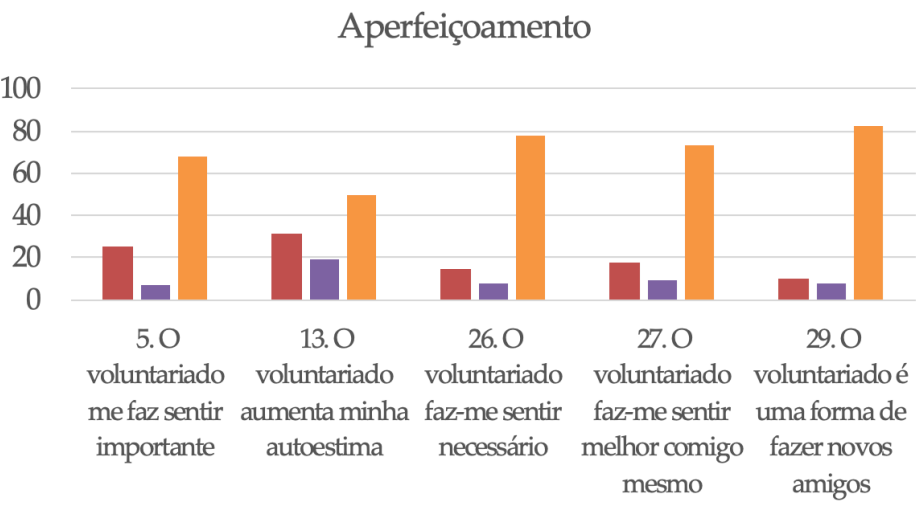

$1-3 \square 4 \square 5-7$ 
Gráfico 4 - Perfil motivacional: Carreira

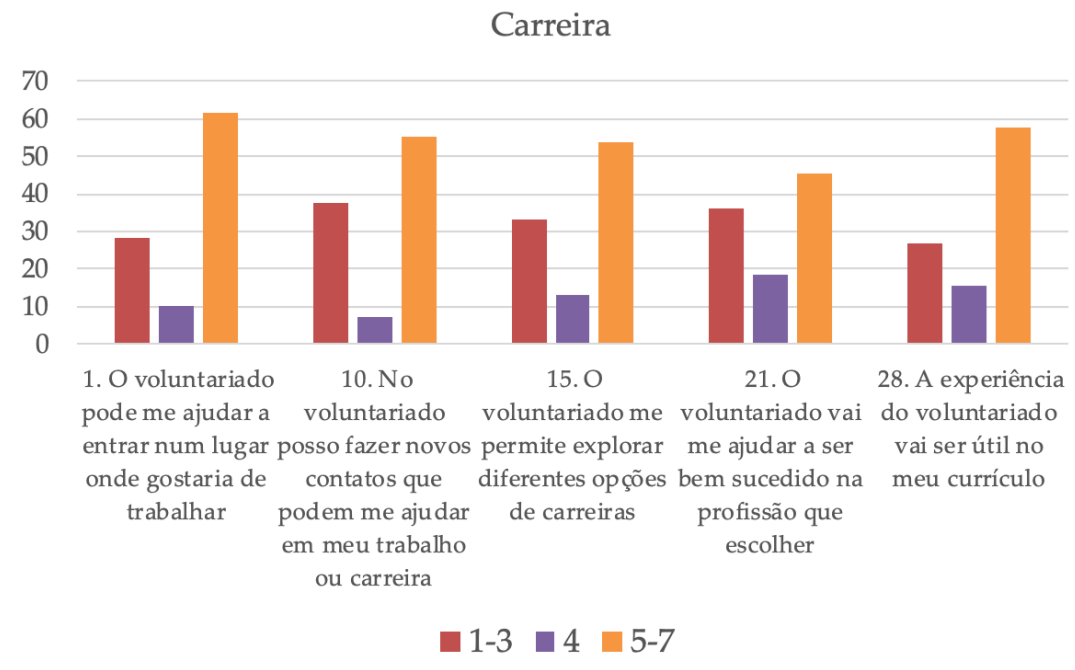

O Gráfico 4 apresenta o perfil Carreira (Q1, Q10, Q15, Q21, Q28), que abrange a visualização de experiências em uma carreira pretendida para a vida, como também benefícios relacionados à estas carreiras. A questão com a maior média de relevância deste perfil é "1. O voluntariado pode me ajudar a entrar num lugar onde gostaria de trabalhar" com 61,54\%, enquanto a questão considerada mais irrelevante é a " 13 . O voluntariado aumenta minha autoestima" com 31,54\%.

Gráfico 5 - Perfil motivacional: Social
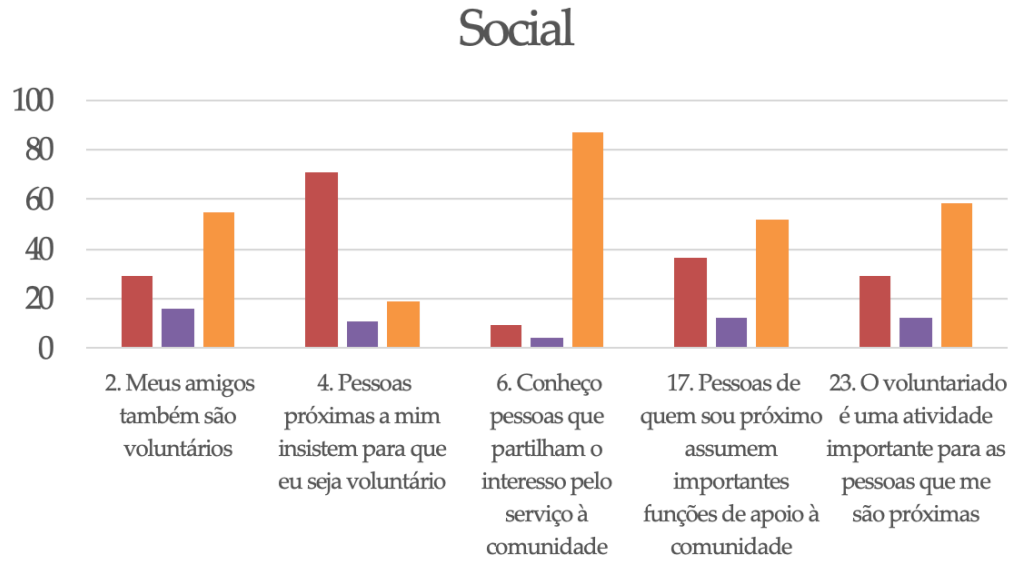

$\square$ 1-3 $\square$ - 5-7

https://doi.org/10.17162/recm.v18i1-2.1159 
O perfil Social (Q2, Q4, Q6, Q17, Q23) é apresentado pelo Gráfico 5, e diz respeito a crença de que dentro do voluntariado será possível desenvolver novos relacionamentos, conhecendo outras pessoas, bem como estreitar laços sociais nos quais já esteja incluído. Neste perfil, a questão que se destaca é "6. Conheço pessoas que partilham o interesse pelo serviço à comunidade" com média de $86,92 \%$ de relevância. Por outro lado, a questão "4. Pessoas próximas a mim insistem para que eu seja voluntário" figura como a segunda maior média de irrelevância dentre toda a pesquisa, com 70,77\%, apresentando um contraste curioso com as demais questões desse perfil.

O sexto e último perfil, apresentado pelo Gráfico 6 é o Protecionismo (Q7, Q9, Q11, Q20, Q24): uma tentativa de proteger o seu próprio ego, a fim de reduzir sentimentos negativos próprios, como culpa, ou minimizar e até mesmo fugir dos problemas pessoais. Comparado com os demais perfis, este apresenta altas médias de irrelevância nas questões, além de suas duas maiores médias estarem relacionadas à irrelevância, tendo a questão "11. Fazer trabalho voluntário pode diminuir a culpa que eu sinto por ser mais afortunado que outros" a maior média de irrelevância dentre toda a pesquisa, com $73,85 \%$. As questões consideradas mais relevantes desse perfil são a "9. Sendo voluntário posso sentir-me menos só" com média de $53,85 \%$ e a "7. Quando me sinto mal, o voluntariado ajuda a esquecer isso" com 53,08\%.

\section{Gráfico 6 - Perfil motivacional: Protecionismo}

\section{Protecionismo}

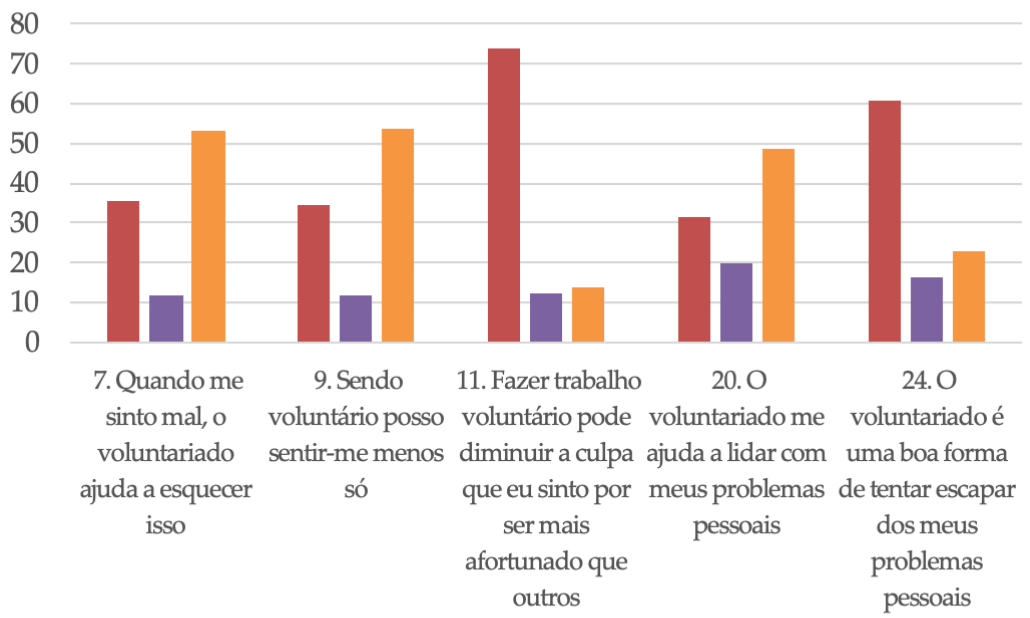

\section{$1-3 \square 4 \square-7$}


Outras percepções surgiram acerca dos resultados analisados, a medida em que foram relacionados aos dados demográficos obtidos. Nota-se algumas curiosidades nas médias das questões respondidas pelo público feminino e masculino, por exemplo "2. Meus amigos também são voluntários" considerada relevante por $59,15 \%$ das mulheres, e por $49,15 \%$ dos homens. A questão "7. Quando me sinto mal, o voluntariado ajuda a esquecer isso" foi considerava relevante por $56,34 \%$ das mulheres, e por $49,15 \%$ dos homens. Já a questão " 24 . O voluntariado é uma boa forma de tentar escapar dos meus problemas pessoais", obteve $13,56 \%$ de relevância entre os homens, em contraste com 30,99\% entre as mulheres. A mesma questão, foi considerada irrelevante para $54,93 \%$ das mulheres e para $67,80 \%$ dos homens.

Quando se observa o fator idade, identifica-se uma pequena variação na classificação geral dos perfis motivacionais. A primeira faixa etária (entre 17 e 23 anos) soma $50 \%$ dos pesquisados, geralmente considerados como aqueles que estão entrando no Ensino Superior, no mercado de trabalho e possivelmente com altas expectativas sobre a dinâmica da vida. Este grupo demonstrou relevância, nas respectivas médias, a questões que compunham os perfis nessa sequência: Valores, 86,77\%; Compreensão, 84\%; Aperfeiçoamento, 73,23\%; Carreira, 60\%; Social, 55,08\%; Protecionismo, $42,77 \%$.

A partir dessa perspectiva, merecem destaque questões como "19. Sinto que é importante ajudar os outros", com média de relevância em 98,46\%, "14. O voluntariado me ajuda a ter uma nova perspectiva sobre as coisas" e "25. No voluntariado posso aprender a lidar com uma variedade de pessoas" que são relevantes para 95,38\% desse público.

Entre os que pertencem a segunda faixa etária (entre 24 e 29 anos), sendo estes $32,3 \%$ dos pesquisados, observa-se a mesma sequência de médias dos perfis motivacionais, onde novamente encontram-se as questões 19 e 25, ambas relevantes para $97,62 \%$ dessa faixa, bem como a questão 14 e "18. $O$ voluntariado me permite aprender coitas diretamente importantes através da experiência", relevantes para $95,24 \%$.

A terceira faixa etária (entre 30 e 68 anos), soma 17,7\% dos pesquisados, e segue a sequência de perfis motivacionais apresentada, com exceção do perfil Social, que supera o perfil Carreira, com médias 56,52\%, 39,13\% respectivamente. O perfil Valores, liderando o ranking de relevância, aparece com média de 93,91\%. Destaca-se também a questão 19 neste perfil, que foi considerada $100 \%$ relevante para este público.

A percepção dos dados da terceira faixa etária traz reflexões acerca de um comportamento voluntário, que está associado a possível estabilidade profissional e acadêmica de pessoas mais maduras, que já alcançaram sua posição no mercado de trabalho, e passaram a se dedicar mais ao vínculo social e relacional, bem como já desenvolveram melhor aceitação pessoal, sabem lidar com suas emoções, conhecem seus problemas pessoais e possivelmente já trabalham nessas resoluções. Hipóteses que também poderiam 
explicar a baixa média de relevância nas questões do perfil Protecionismo: $25,22 \%$.

Por outro lado, as questões "11. Fazer trabalho voluntário pode diminuir a culpa que eu sinto por ser mais afortunado que outros" e "24. O voluntariado é uma boa forma de tentar escapar dos meus problemas pessoais" foram consideradas as mais irrelevantes em todas as faixas etárias, a maior média foi para a terceira faixa etária, ambas obtiveram 73,91\%.

Com relação a religiosidade, dentre os $4,6 \%$ que declararam não praticar nenhuma religião, algumas questões foram consideradas como 100\% relevantes: "3. Estou preocupado com aqueles que são menos afortunados que eu"; "6. Conheço pessoas que partilham o interesso pelo serviço à comunidade"; " 14 . O voluntariado me ajuda a ter uma nova perspectiva sobre as coisas"; "16. Sinto compaixão pelas pessoas com necessidade"; "18. O voluntariado me permite aprender coitas diretamente importantes através da experiência"; "19. Sinto que é importante ajudar os outros"; "25. No voluntariado posso aprender a lidar com uma variedade de pessoas"; e, "27. O voluntariado faz-me sentir melhor comigo mesmo". Já a questão "4. Pessoas próximas a mim insistem para que eu seja voluntário" foi considerada como $0 \%$ relevante para esse público.

Analisando o fator tempo de envolvimento no voluntariado, observa-se que dentre aqueles que dedicaram período superior a 12 meses em projetos voluntários, 7,7\% dos pesquisados, o perfil Compreensão obteve média de relevância de $84 \%$, seguido pelos perfis Valores $(80 \%)$, Carreira $(56 \%)$, Aperfeiçoamento (54\%), Social (44\%) e Protecionismo (26\%). Possivelmente esses voluntários tenham se envolvido nesses projetos de longa duração por buscarem uma nova perspectiva sobre a vida, relacionamentos, pessoas, e sobre si próprio, e entenderam que somente um tempo razoável como este lhes permitiria essa reflexão.

Outro aspecto desse público de voluntários de longa duração é que $90 \%$ deles consideram como irrelevante a questão "24. O voluntariado é uma boa forma de tentar escapar dos meus problemas pessoais". De certa forma, a dedicação ao voluntariado por tal período, e consequentemente a mudança significativa na rotina, no círculo de amigos, no distanciamento da família, na nova convivência, no processo de aculturação, demandam certa estabilidade emocional e até mesmo um nível relevante de maturidade.

Para os voluntários de curto prazo, com experiências de até 30 dias, destaca-se duas questões muito relevantes, ambas com 90,43\% de média: “3. Estou preocupado com aqueles que são menos afortunados que eu" e "22. Ao ser voluntário posso fazer algo por uma causa que é importante para mim". É possível refletir que esses voluntários, ao escolherem essa experiência, dispondo-se do tempo, dedicação e recursos que julgaram ser suficientes e necessários, também ofereceram o melhor que puderam. Eventualmente adaptaram por um curto período a sua agenda e a sua rotina, na expectativa de contribuir 
efetivamente com o voluntariado. Não importa o tempo da experiência, desde que haja envolvimento verdadeiro.

\section{Gráfico 7 - Média geral dos perfis motivacionais}

\section{Perfis Motivacionais}

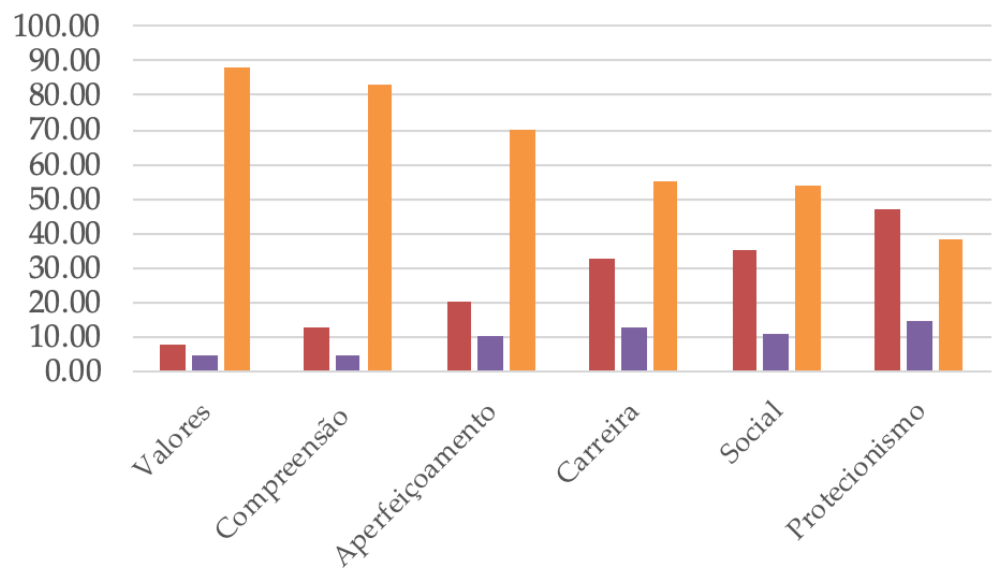

$1-3 \square 4 \square-7$

Tabela 1 - Médias gerais dos perfis motivacionais

\begin{tabular}{|l|r|r|r|}
\hline & \multicolumn{1}{|c|}{$\mathbf{1 - 3}$} & \multicolumn{1}{c|}{$\mathbf{4}$} & \multicolumn{1}{c|}{$\mathbf{5 - 7}$} \\
\hline Valores & 7,38 & 4,46 & 88,15 \\
\hline Compreensão & 12,77 & 4,31 & 82,92 \\
\hline Aperfeiçoamento & 19,85 & 10,15 & 70,00 \\
\hline Carreira & 32,46 & 12,77 & 54,77 \\
\hline Social & 34,92 & 11,08 & 54,00 \\
\hline Protecionismo & 47,23 & 14,31 & 38,46 \\
\hline
\end{tabular}

Observando de maneira geral os perfis motivacionais, apresentados pelo Gráfico 7 e Tabela 1, nota-se que o perfil Valores foi considerado como o mais relevante na prática do voluntariado por $88,15 \%$ dos pesquisados. Em seguida na média de relevância, figura o perfil Compreensão, com $82,92 \%$.

Na outra extremidade percebe-se o perfil Protecionismo, que não obteve média superior a $50 \%$ em nenhuma opção. Seu destaque é para sua média de irrelevância, a maior dentre todos os perfis: $47,23 \%$. Por curiosidade, os pesquisados demonstraram maior neutralidade sobre questões desse perfil, 
mais precisamente $14,31 \%$ deles, o que permite especulações, como a possibilidade de supressão do ego, a carência pessoal de encontrar atividades para se dedicar, ou talvez o reconhecimento da necessidade de uma reconstrução emocional.

Em síntese, o voluntariado é mantido por indivíduos preocupados com a sociedade, que expressam o humanitarismo e altruísmo; por aqueles que desejam intensamente viver experiências de aprendizado e exercitar o conhecimento e as habilidades; e ainda, por aqueles em busca de aperfeiçoamento pessoal e crescimento individual ${ }^{57}$.

Por outro lado, perfis como Protecionismo, Social e Carreira mesmo significativos, não demonstraram ser fatores elementares na motivação ao voluntariado. Permite-se entender que que o engajamento de voluntários não está inerentemente atrelado apenas aos interesses pessoais e egoístas dos indivíduos, sendo eles parte do processo motivacional, mas não como princípios norteadores.

Todos esses elementos lançam luz significativa sobre os processos que envolvem o voluntariado, desde a atração de voluntários, recrutamento, retenção, manutenção e avaliação. É de extrema importância que sejam considerados e colocados em prática nos projetos, formais, informais, de curto ou longo prazo, afinal, são lições valiosíssimas, que se extraídas e aplicadas de maneira correta, podem frutificar inimaginavelmente.

\section{Considerações finais}

O voluntariado é parte da vivência da sociedade há séculos, mas apenas nas últimas décadas ganhou notoriedade em estudos e pesquisas de forma sistemática. É um tema que abrange teorias extensas e bastante valiosas, mas encontra dificuldades quando posto em prática, afinal, é a arte de lidar com seres humanos. Ao se aprofundar neste assunto, é importante ressaltar essa delicadeza do voluntariado, que não detém relações obrigatórias, tampouco vínculos empregatícios, praticamente zero recompensas financeiras.

Compreender as individualidades dos voluntários, bem como as esferas sociais nas quais estejam incluídos, e identificar suas pretensões, propósitos e por fim seus perfis motivacionais, tende a alcançar sucesso na expectativa de atração e recrutamento de voluntários, como também na própria retenção deles em novos projetos. Não há uma fórmula ou receita específica para seguir, pois cada voluntário é único e precisa ser percebido na sua individualidade, com suas qualificações, desejos, e aspirações ao trabalho voluntário. Esses elementos individuais devem ser conciliados aos projetos nos quais se pretende introduzi-los, em síntese, criar a associação entre os perfis

57 Clary, Snyder e Ridge, “Volunteers Motivations”, 333-350.

https://doi.org/10.17162/recm.v18i1-2.1159 
motivacionais e as devidas práticas voluntárias, o que chamamos de articulação motivacional.

Há de se lembrar que a motivação, mesmo inconsciente, está intimamente relacionada a expectativa de recompensa. De certa forma, é imperativo que organizações voluntárias, formais ou informais, que necessitam de capital humano, identifiquem e ofereçam aos candidatos aquilo que essencialmente buscam encontrar. Instigar e estimular o voluntariado a partir de elementos relevantes aos próprios voluntários, que de acordo com esse estudo são: (1) valores - expressão de humanitarismo e altruísmo, defendidos por indivíduos preocupados com a sociedade; (2) compreensão - a possibilidade de exercitar o conhecimento e habilidades, buscando por experiências de aprendizado; e, (3) aperfeiçoamento - a pretensão de desenvolvimento pessoal, associado ao crescimento individual e autoestima, envolvendo sentimentos positivos acerca de si mesmo.

É possível perceber com isso que os voluntários, ainda que em busca de satisfazer possíveis desejos egoístas, mantiveram em sua maioria o desejo de manifestar o altruísmo e agir com bondade para com os outros. Todos os seis perfis motivacionais propostos na pesquisa, relevantes ou irrelevantes, devem receber atenção especial na gestão de pessoas, pois contribuem, na sua devida esfera de atuação, de forma intensa com o recrutamento, atração e retenção no voluntariado, promovendo o engajamento necessário nos voluntários para satisfazer aos projetos.

Gerencialmente falando, essa atração e recrutamento deve ser baseada em uma clara comunicação entre organizações formais ou informais e os voluntários, com honestidade sobre as expectativas e as contribuições de ambos os lados. Ao idealizarem novos projetos, essas organizações devem refletir sobre elementos importantes desse processo, como a publicidade, $\mathrm{o}$ contato com voluntários, a forma como trata-los e como apresentar-lhes os projetos, os critérios necessários para sua realização, os compromissos que devem ser firmados, as expectativas a serem supridas, além é claro das características de tempo, recursos e habilidades.

Essa é uma postura que busca o máximo e desobstruído engajamento de voluntários, que estejam conscientes do que deles é esperado e o que podem alcançar. Também é importante lembrar que o sucesso de um projeto não está necessariamente associado a quantidade de voluntários participantes, mas ao compromisso demonstrado e firmado por eles. É preferível manter um projeto com poucos voluntários comprometidos, a ter o dobro de voluntários descomprometidos.

Experiências vividas em outros projetos, por líderes e liderados, quando bem evidenciadas também facilitam a aproximação de novos voluntários, que podem avaliar e assimilar o voluntariado à sua própria realidade. Por isso, é importante que todos, dentro de um projeto, vivenciem de forma 
intensa seus propósitos fundamentais, a fim de criar identificação, pertencimento e unidade, influenciando a permanência e a atração de novos voluntários.

Também se compreende que uma grande parcela da sociedade ainda não teve uma experiência de voluntariado, e absolutamente não sabe como funciona. Dentre esses, é possível haver aqueles que gostariam de experimentar, e outros que não creem ter as competências e habilidades necessárias. A motivação e o preparo que lhes falta podem ser despertados por uma conversa informal, publicidade, treinamentos, materiais, parcerias, entre tantas outras formas.

Entende-se as limitações dessa pesquisa, aplicada a voluntários associados a apenas uma instituição mantenedora de projetos, que eventualmente mantém uma cultura específica de voluntariado, e pode ter influenciado as percepções dos pesquisados, bem como os perfis demográficos tão similares. Propostas de estudos futuros podem envolver a realização da pesquisa em mais de uma instituição, com realidades diferentes, possibilitando a observação de maior diversidade de perfis demográficos, e até mesmo os perfis motivacionais. Outras opções são relacionadas a identificação de perfis motivacionais entre os líderes de projetos voluntários, e as razões pelas quais os indivíduos investem seus recursos financeiros sem tomar participação ativa em projetos de voluntariado.

Conclui-se este estudo de maneira satisfatória, identificados os perfis motivacionais e as razões pelas quais indivíduos se engajam em atividades de voluntariado, que serviram para reflexões acerca da gestão de pessoas por meio da atração, recrutamento e retenção de voluntários, e propostas que tornem esses processos mais eficientes e significativos para os líderes e liderados envolvidos em projetos de voluntariado. 